\title{
Stock returns, seasonality and asymmetric conditional volatility in world equity markets
}

\section{Ercan Balaban , Asli Bayar \& Özgür Berk Kan}

To cite this article: Ercan Balaban , Asli Bayar \& Özgür Berk Kan (2001) Stock returns, seasonality and asymmetric conditional volatility in world equity markets, Applied Economics Letters, 8:4, 263-268, DOI: 10.1080/135048501750104051

To link to this article: http://dx.doi.org/10.1080/135048501750104051

\section{Published online: 06 Oct 2010.}

Submit your article to this journal $\pi$

Lll Article views: 140

Q View related articles $\circlearrowright$

4 Citing articles: 25 View citing articles $ત$ 


\title{
Stock returns, seasonality and asymmetric conditional volatility in world equity
}

\section{markets}

\author{
ERCAN BALABAN* $*$, ASLI BAYAR $\S$ and ÖZGÜR BERK KAN \\ Deniz Yatirim Securities Inc., Istanbul 80496, Turkey, †Johann Wolfgang Goethe \\ University, Frankfurt/M. 60325, Germany, §Bilkent University, Ankara 06533, \\ Turkey and - State University of New York-New Paltz, NY 12561, USA
}

The paper tests four hypotheses at the same time using an autoregressive returngenerating process and an asymmetric conditional variance specification, both also including deterministic day of the week dummies. The daily stock index returns from 19 countries are employed to test: $(\mathrm{H} 1)$ predictable time variation in conditional volatility; (H2) asymmetry in volatility and leverage effect; $(\mathrm{H} 3)$ effects of estimated volatility on returns; and (H4) day of the week effects on both returns and their volatility. Evidence is provided for predictable time varying daily volatility in all markets among which eight also exhibit a significant leverage effect. There is a significantly positive relationship between returns and their conditional volatility in only three countries. The nature of the day of the week effects on returns and their conditional volatility differs greatly among countries and across days. Thirteen countries exhibit seasonality in either mean returns (seven countries) or volatility (eight countries) or both (two countries). Each day is at least once reported to exhibit significant positive and negative effects in both mean and volatility with the exception that there is no negative effect on mean returns and no positive effect in volatility on Wednesdays.

\section{INTRODUCTION}

This study presents international evidence for four hypotheses using daily stock index returns denominated in US dollars from 19 countries: (H1) predictable time variation in conditional volatility; (H2) asymmetry in conditional volatility and leverage effect; (H3) effects of estimated conditional volatility on returns; and $(\mathrm{H} 4)$ day of the week effects on both returns and their conditional volatility.

Previous research has investigated one or more of the above issues using data from one country or more, but not all of them at the same time employing international data. The standard ARCH/GARCH class of models has been a major tool in modelling predictability and time variation in the volatility of financial asset returns (H1) (see Bollerslev et al., 1992, and Bollerslev et al., 1994 for recent surveys of volatility clustering). In a daily GARCH model, the conditional volatility depends on yesterday's conditional volatility and yesterday's squared forecast error. The estimated volatility is symmetric; i.e. the forecast errors whether positive or negative have the same effect on the conditional volatility. Put differently, the predicted variance depends on only the magnitude of previous shock(s) and not on the sign. However, it is well documented in the literature that negative shocks may have a different impact on volatility (H2) (Black, 1976; Christie, 1982; Nelson, 1991; Glosten et al., 1993; Zakoian, 1994).

*Corresponding author. E-mail: ercan_balaban@yahoo.com 
For example, according to the so-called leverage effect after Black (1976), negative shocks increase volatility more than do positive shocks of equal magnitude. Engle and $\mathrm{Ng}$ (1993) claim that the GJR-GARCH model of Glosten et al. (1993), which explicitly incorporates asymmetry into volatility or allows different effects on volatility for positive and negative forecast errors, better fits stock market data. In addition, Brailsford and Faff (1996) find that the GJR-GARCH model has a superior outof-sample performance when forecasting stock market volatility.

The research on the relationship between stock returns and their conditional volatility $(\mathrm{H} 3)$ has not reached a consensus. For the US market, French et al. (1987) and Campbell and Hentschel (1992) report a positive relation whereas Nelson (1991) and Glosten et al. (1993) find a negative one. ${ }^{1}$ Baillie and DeGennaro (1990) and Chan et al. (1992) report no significant relation. International evidence is provided for a zero relation for three countries by Corhay and Rad (1994) and for ten countries by Theodossiou and Lee (1995). Additionally, Duffee (1995) provides evidence of firm-level relations.

International evidence for day of the week effects (H4) in the stock markets of 19 countries has recently been reported by Agrawal and Tandon (1994), and Bayar and Kan (1999). ${ }^{2}$ Agrawal and Tandon (1994) find large, positive mean returns on Fridays and Wednesdays in most of the countries. They observe lower or negative mean returns on Mondays and Tuesdays, and higher and positive returns from Wednesday to Friday in almost all countries. Bayar and Kan (1999) report a higher pattern around the middle of the week, Wednesday and then Tuesday; and a lower one towards the end of the week, Thursday and then Friday. The highest (lowest) volatility is observed on Mondays (Tuesdays).

The above four hypotheses are tested for a more recent period of time using an asymmetric conditional volatilityin-mean model, namely the AR(p)-GJR-GARCH(1,1)-M specification, modified by introducing daily dummies in both conditional mean and conditional volatility functions, for which the details are given in the following section. The empirical findings are summarized in Section III. Section IV concludes.

\section{DATA AND RESEARCH DESIGN}

The sample covers daily observations of stock market indices from 19 countries [Australia (AUS), Austria (AST), Belgium (BEL), Canada (CAN), Denmark (DEN), Finland (FIN), France (FRA), Germany (GER), Hong Kong (HON), Italy (ITA), Japan (JAP), The Netherlands (NET), New Zealand (NZ), Norway (NOR), Spain (SPA), Sweden (SWE), Switzerland (SWI), the UK, and the USA] for the period 20 July 1993 to 1 July 1998. Daily stock market indices in terms of the US dollars, ${ }^{3}$ calculated by the Morgan Stanley Capital International Index, are obtained from DataStream, which provides adjusted market value weighted composite indices using daily closing prices.

The AR(p)-GJR-GARCH(1,1)- M model with the daily dummies allows simultaneous testing the time variation and asymmetry in volatility, the day of the week effects on both the conditional first and second moments of daily index returns together with the effects of estimated conditional volatility on these returns. We estimate the following conditional mean and conditional volatility functions for each country:

$$
\begin{aligned}
& R_{t}=\gamma h_{t}+c+\sum_{i=2}^{5} \lambda_{i} D_{i t}+\sum_{i=1}^{n} \Psi_{j} R_{t-i}+\varepsilon_{t} \\
& h_{t}^{2}=\theta+\alpha^{+} \varepsilon_{t-1}^{2}+\alpha^{-} \varepsilon_{t-1}^{2} K_{t-1}+\beta h_{t-1}^{2} \sum_{i=2}^{5} \delta_{i} D_{i t}
\end{aligned}
$$

$\varepsilon_{t} I \varphi_{t-1} \sim N\left(0, h_{t}^{2}\right)$

where $R_{t}$ is the continuously compounded daily index return on day $t$ (1291 observations). The autoregressive terms in the mean equation account for statistically significant but economically minor autocorrelation and correct for possible effects of non-synchronous trading and/or price limits, if any. ${ }^{4} D_{i t}$ is a binary dummy variable such that $D_{2 t}=1$ if day $t$ is a Tuesday and 0 otherwise; $D_{3 t}=1$ if day $t$ is a Wednesday and 0 otherwise; and so on. The coefficients $\lambda_{i}\left(\delta_{i}\right)$ show the difference of mean returns (volatility) on Tuesday-Friday from that of Monday after correcting for autocorrelation and heteroscedasticity. ${ }^{5}$ If there are no differences among index returns and their volatility across days of the week, for all $i, \lambda_{i}$ and $\delta_{i}$ should be zero, respectively (Hsieh, 1988; Copeland and Wang,

\footnotetext{
${ }^{1}$ A positive as well as a negative relation would be consistent with the theory. See Glosten et al. (1993).

${ }^{2}$ Jaffe and Westerfield (1985), Aggarwal and Rivoli (1989), Wong et al. (1992), Peiro (1994) and Dubois and Louvet (1996) provide international evidence, many others provide evidence for only one country.

${ }^{3}$ Using dollar returns instead of domestic currency returns eliminates possible effects of exchange rate fluctuations and makes the results comparable across countries from the point of view of investors who diversify internationally. The results for local returns and any other referred but not reported findings to save on space are available upon request.

${ }^{4}$ The number of lags is chosen according to the Akaike Information Criterion and Schwartz Criterion.

${ }^{5} \mathrm{We}$ also ran the GARCH(1,1)-M and the GJR-GARCH(1,1)-M models without the daily dummies in the variance function. In this case, we obtained in general higher coefficients for persistency in volatility. The higher order models are insignificant and do not improve the loglikelihood (LogL) function.
} 
1994; Balaban, 1999). ${ }^{6}$ The effect of the estimated conditional standard deviation on returns is given by $\gamma$ of which expected sign is positive for a risk-averse investor. ${ }^{7}$ $K_{t-1}$ is a dummy variable taking the value of 1 if the previous day's forecast error is negative; i.e. $\varepsilon_{t-1}<0$, and 0 otherwise. If the coefficient $\alpha^{-}$significantly differs from zero, the null of no asymmetry in conditional volatility is rejected. ${ }^{8}$ A significantly positive $\alpha^{-}$shows the existence of leverage effect. We assume that forecast errors are conditionally normal distributed with zero mean and variance $h_{t}^{2}$. All estimations are made using quasi-maximum likelihood (Bollerslev and Wooldridge, 1992). ${ }^{9}$

We test $(\mathrm{H} 1)$ predictable time variation in volatility $\left[\alpha^{+}>0\right.$, and/or $\alpha^{-} \neq 0$, and/or $\left.\beta>0\right]$, (H2) asymmetry in conditional volatility $\left.\alpha^{-} \neq 0\right]$, and leverage effect $\left.\left[\alpha^{-}>0\right]\right]$, (H3) effects of estimated conditional volatility on returns $[\gamma \neq 0]$, and $(\mathrm{H} 4)$ day of the week effects on stock index returns and/or their volatility $\left[\lambda_{i} \neq 0\right.$ for some $i$, and/or $\delta_{i} \neq 0$ for some $i$ ]. It should be noted that each hypothesis is separately tested.

\section{EMPIRICAL RESULTS}

Table 1 presents the estimation results of the GJRGARCH(1,1)-M models. Note that stock market volatility is time varying and predictable in all countries. The estimated GARCH term is always significantly positive $(\beta>0)$ at the $1 \%$ level and ranges between 0.607 (Belgium) and 0.960 (Denmark). The mean and median $\beta$ values are 0.710 and 0.724 , respectively, and well approximated by Italy and Switzerland. The coefficient for positive forecast errors is significantly positive $\left(\alpha^{+}>0\right)$ at least at the $5 \%$ level in ten countries. These significant $\alpha^{+}$values range between 0.045 (Italy) and 0.169 (Japan). The asymmetric coefficient is significantly positive $\left(\alpha^{-}>0\right)$ at least at the $10 \%$ level in eight countries, providing evidence for the leverage effect, and negative but insignificant only for Denmark. The significant $\alpha^{-}$ranges between 0.050 (Canada) and 0.233 (USA). The estimated $\theta$ is significant at the $1 \%$ level (Belgium, Italy and Norway), at the $5 \%$ level (France and Switzerland), and at the 10\% level (Australia, Hong Kong and The Netherlands).

Table 2 summarizes the results of seasonality and asymmetry across countries. There is neither seasonality in the dollar denominated index returns and their conditional volatility nor asymmetry in conditional volatility in five countries, namely Australia, Finland, Spain, Sweden and the UK [row I]. In addition, there is a zero relation between conditional volatility and returns. This suggests that index returns in these countries can be modelled as an AR(p)GARCH $(1,1)$ stochastic process. ${ }^{10}$ On the other hand, evidence is found for asymmetric volatility and seasonality in both mean and volatility only in the USA [row VIII]. The leverage effect is significant at the $1 \%$ level. There is no asymmetry but seasonality only in mean (volatility) in Japan, The Netherlands and New Zealand (Belgium and Denmark) [rows II and III]. There is no asymmetry but seasonality in both mean and volatility only in Austria [row IV]. We find no seasonality either in mean or volatility but asymmetry in volatility only in Canada [row V].

The leverage effect is significant at the $10 \%$ level. Germany and Hong Kong exhibit asymmetry in volatility and seasonality only in mean [row VI]. The leverage effect is significant at the 5\% level. Four countries (France, Italy, Norway and Switzerland) have asymmetry in volatility and seasonality only in volatility [row VII]. Note that among eight countries that have asymmetric volatility only in Italy is the estimated volatility coefficient for positive forecast errors also significant at the 5\% level.

The estimated conditional volatility in terms standard deviation has a positive and significant effect on the index returns in three countries (Austria (1\%), Canada (1\%), and Japan $(10 \%)$ ), a negative but insignificant effect only in Finland, and a positive but insignificant effect in the rest of the sample. This implies that conditional standard deviation may not be an appropriate specification of risk.

The nature of the day of the week effects differs greatly among countries and across days. In six countries (Australia, Canada, Finland, Spain, Sweden and the UK), we do not report any daily effects [rows I and V]. Among these countries, only Canada exhibits a leverage effect significant at the $10 \%$ level. Therefore, an AR(p)$\operatorname{GARCH}(1,1)$ model without any daily dummies is sufficient for all these countries but Canada where an AR(p)GJR-GARCH(1,1)-M model fits better. Thirteen countries exhibit seasonality in either mean returns or volatility or both. Day of the week effects only on mean returns exist in three countries (Japan, The Netherlands and New Zealand)

\footnotetext{
${ }^{6}$ All estimated models obey the standard assumptions of stationarity and non-negativity of the conditional variance. If $\delta_{i}<0$ for some $i$, it is theoretically possible to obtain a negative variance. However, these estimated dummy coefficients are very small compared to the persistency coefficients. We check this possibility and never obtain a negative estimate of conditional variance.

${ }^{7}$ French et al. (1987) suggest standard deviation specification. We employed also variance specification for which the results do not change. See Glosten et al. (1993) for a discussion.

${ }^{8}$ We also ran a GARCH(1,1)-M model and employed the sign bias tests introduced by Engle and $\mathrm{Ng}$ (1993). We report that the asymmetric coefficient is significant in those GJR models for which the results of the sign bias tests also suggest asymmetry in conditional volatility, and vice versa.

9 The standardized residuals $\left(\mathrm{e}_{t} / h_{t}\right)$ and their squared values from all models always obey the standard assumptions of no autocorrelation and no heteroscedasticity although the $\left(\mathrm{e}_{t} / h_{t}\right)$ are not normally distributed.

${ }^{10}$ The AR(1) term is positive and significant in almost all countries. The higher order terms are usually found negatively significant implying mean reversion and reflecting the correlation of five trading days, as expected. These results are consisted with the others reported elsewhere.
} 
with no asymmetry in conditional volatility [row II], and in two countries (Germany and Hong Kong) with a leverage effect significant at the 5\% level [row VI]. Day of the week effects only on volatility are observed in two countries (Belgium and Denmark) with no asymmetry in conditional volatility [row III], and in four countries (France, Italy, Norway and Switzerland) with a leverage effect significant at least at the $10 \%$ level [row VII]. Austria is the only country with no asymmetry in volatility but daily effects both on returns and volatility [row IV]. The only country with a leverage effect (significant at the 1\% level) and daily effects both on returns and volatility is the USA [row VIII].

Table 3 shows that each day is at least once reported to exhibit significant positive and negative effects in both mean and volatility with the exception that there is no negative effect on mean returns and no positive effect in volatility on Wednesdays. However, we cannot find a general pattern and the previously reported anomalies seem to disappear if one controls for autocorrelation and heteroscedasticity.
The positive day of the week effects on mean returns can be summarized as follows: on Tuesdays (Japan), on Wednesdays (Hong Kong, Japan and New Zealand), on Thursdays (Japan and New Zealand), and on Fridays (New Zealand). The negative daily effects on mean returns are observed on Tuesdays (Austria, Germany and The Netherlands), on Thursdays (the Netherlands and New Zealand), and on Fridays (Austria and Germany). The Monday returns are negative in fourteen countries but significant only in Austria, Canada, Japan and New Zealand.

The positive day of the week effects in conditional volatility are found on Tuesdays (Austria), on Thursdays (Austria, Denmark and the USA), and on Fridays (Austria). The negative daily effects in volatility are on Tuesdays (Belgium, Denmark, France, Italy and Switzerland), on Wednesdays and Thursdays (Italy), and on Fridays (Italy and Norway). The highest volatility is observed in eight countries on Mondays (Australia, Belgium, France, Hong Kong, Italy, the Netherlands, Norway and Switzerland), in two countries on Thursdays

Table 1. The GJR-GARCH(1,1)-M estimation results

\begin{tabular}{|c|c|c|c|c|c|c|c|c|c|c|c|c|c|c|c|c|c|c|c|c|}
\hline & & AUS & AST & BEL & CAN & DEN & J FIN & RA & I GER & $\mathrm{HON}$ & J ITA & JAP & NET & $\mathrm{NZ}$ & NOR & SPA & SWE & SWI & I UK & USA \\
\hline & a & & 1 & 24 & & 02 & 0.0 & & & & & & & & & & & & 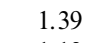 & .09 \\
\hline & o & & & 0.16 & & 11 & 0.17 & 0.35 & & 0.0 & & & & & & & & & 1.13 & 0.12 \\
\hline & c & -3.00 & $-7.99^{1}$ & -0.85 & -4.3 & 0.95 & 0.8 & -2.55 & -0.20 & -1.93 & -1.00 & $-3.86^{1}$ & 0.48 & $-5.85^{2}$ & ${ }^{2}-2.70$ & -2.11 & 1.02 & $-3.39-$ & -10.00 & 0.25 \\
\hline & c & 2.35 & 25 & 1.51 & 2.5 & 0.93 & & 3.69 & & 1.52 & & & & & 4.07 & & & 2.95 & 64 & 0.75 \\
\hline \multirow[t]{2}{*}{$D_{2}$} & 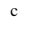 & 0.23 & $-2.37^{3}$ & -0.68 & 0.67 & -0.66 & 0.60 & 0.96 & $-1.64^{3}$ & 0.90 & 1.96 & & $-2.47^{1}$ & 2.14 & -0.42 & 0.76 & -1.69 & -0.02 & 0.54 & -0.10 \\
\hline & c & 0.96 & 1.29 & 0.74 & 1.21 & 0.77 & 1. & 1.03 & 0.85 & 1. & 1.35 & & 0.81 & & 1. & 1.14 & 1.07 & 1.22 & 1.16 & 0.55 \\
\hline \multirow[t]{2}{*}{$D_{3}$} & c & 1.60 & -0.66 & -0.14 & 0.8 & -0.23 & & 1. & & & 0.27 & & -1.03 & & 0.57 & -0.01 & -1 & & 0.67 & -0.02 \\
\hline & c & 0 & 1.1 & 0.76 & 1. & & & 0.97 & & 1. & & & & & & & & & 19 & 0.54 \\
\hline \multirow[t]{2}{*}{$D_{4}$} & 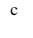 & 1.01 & -1.27 & -0.62 & -0.6 & -0.5 & 0 & -0.51 & -1.36 & -1 & & & -2 & & ${ }^{2}-0$ & & -1 & & & -1.02 \\
\hline & c & 0.99 & 1.14 & 0.75 & 1.3 & 0.7 & & 0.95 & & & & & & & & & & & & 0.58 \\
\hline \multirow[t]{2}{*}{$D$} & c & 0.7 & $-2.94^{2}$ & -0.05 & 0 . & -0.66 & & 0.49 & -1 & & & & -1 . & & & & & & & 0.30 \\
\hline & 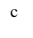 & & 1.4 & 0.74 & & 0.7 & & 0.96 & & & & & 0 . & & & & & & & 0.64 \\
\hline \multirow[t]{2}{*}{$R_{\mathrm{t}-1}$} & & 0. & 0.0 & 0.04 & & - & & - & -0 & & $0.10^{1}$ & $1-$ & - & & & & & & & $0.12^{1}$ \\
\hline & & 0 . & 0.0 & 0.03 & 0.0 & & 0.03 & & & & 0.03 & & & & 0. & & 0 . & 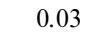 & & 0.03 \\
\hline \multicolumn{2}{|l|}{$R_{\mathrm{t}-3}$} & - & - & - & - & - & - & 0. & - & & - & - & - & - & - & - & - & - & - & - \\
\hline \multirow{2}{*}{\multicolumn{2}{|c|}{$R_{\mathrm{t}-5}$}} & - & - & $-0.12^{1}$ & - & - & - & - & - & - & - & 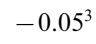 & - & - & - & & & -0 & & $-0.10^{1}$ \\
\hline & & & & 0.0 & & & & & & & & & & & & & & & & 3 \\
\hline & d & $3.62^{3}$ & -0.8 & 2.93 & & 1.2 & & $3.37^{2}$ & & $5.71^{3}$ & 10.0 & & 2 & & $5.16^{1}$ & & & & & -0.77 \\
\hline & d & 2 & & & & & & & & & & & & & & & & & & 0.67 \\
\hline \multirow{2}{*}{\multicolumn{2}{|c|}{$e_{t-1}^{2}(+)$}} & 0 & 0 . & $0.15^{1}$ & & & & & & & $5^{2}$ & & & & & $6^{1}$ & & & & 02 \\
\hline & & & & & & & & & & & & & & & & & & & & 3 \\
\hline \multirow{2}{*}{\multicolumn{2}{|c|}{$e_{t-1}^{2}(-)$}} & 0. & & 0 & & 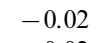 & & & & & 0 . & & & & 0 . & & & & 0 & $0.23^{1}$ \\
\hline & & & & 0 & & & & & & & & & & & & & & & & 0.08 \\
\hline \multirow{2}{*}{\multicolumn{2}{|c|}{$h_{\mathrm{t}-1}^{2}$}} & & 0 & 1 & & & & & & & & & & & & & & & & $0.76^{1}$ \\
\hline & & 0 . & 0 & 0.10 & & 0.01 & & & & 0.11 & & & & 0.11 & 0.13 & 4 & 0.04 & & 0.19 & 0.06 \\
\hline \multirow[t]{2}{*}{$D_{2}$} & 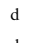 & -39 & $4.74^{2}$ & $-3.50^{2}$ & -1.75 & $2.43^{3}$ & -2. & $-4.32^{3}$ & -3.06 & -6.91 & $-13.10^{2}$ & -4.42 & $-2.03-$ & -10.90 & 0.51 & -5.47 & -0.22 & $-5.58^{2}$ & 0.27 & $1.73^{3}$ \\
\hline & d & & 1.9 & 1.4 & & & & & & & 616 & & & & & & & & & 0.93 \\
\hline \multirow[t]{2}{*}{$D_{3}$} & d & -0 . & 1.8 & -1.49 & -2.2 & t & & 0.72 & -1.16 & 3. & $-9.96^{2}$ & 1. & -1 . & 9 & -3.30 & -2.94 & -1.77 & -2 & & \\
\hline & d & 1. & & 1.14 & 1.9 & & & & & 3. & 398 & & & & 2. & 2.96 & 2. & 1. & & 0.74 \\
\hline \multirow[t]{2}{*}{$D_{4}$} & d & -1.91 & $2.82^{2}$ & -1.25 & -0.89 & 2.7 & 0. & -1.15 & -1.30 & -3.74 & $-8.22^{2}$ & $2-1.99$ & 0.01 & -8.89 & -2.02 & -4.60 & 0 . & 0. & 1. & $2.34^{1}$ \\
\hline & d & 1.9 & 1.4 & 1.12 & & 1.1 & & 1. & & 3. & 4.00 & & 1. & & 1.77 & 2. & 2.46 & & & 0.80 \\
\hline \multirow[t]{2}{*}{$D_{5}$} & d & 0.79 & 6.1 & -0.71 & -0.9 & 1.57 & -1.99 & -2.3 & 0.85 & -5.70 & $-8.39^{3}$ & -0.37 & -0.56 & -2.48 & $-3.11^{3}$ & -2.62 & 3.03 & -2.46 & 1.10 & 2.02 \\
\hline & d & 2.23 & 1.67 & 1.41 & 2.09 & 1.51 & 4.63 & 2.01 & 2.06 & 4.22 & 4.38 & 2.47 & 1.51 & 5.33 & 1.86 & 3.15 & 3.24 & 2.04 & 1.31 & 1.23 \\
\hline IVEL & & & & & & & & & & 500 & 3684 & & & & 7002 & & & & 4433 & 5889 \\
\hline
\end{tabular}

Notes: ${ }^{\mathrm{a}}$ The estimated coefficient, ${ }^{\mathrm{b}}$ The Bollerslev-Woodlridge (1992) robust standard errors. ${ }^{\mathrm{c}}$ and ${ }^{\mathrm{d}}$ must be multipled by $10^{-3}$ and $10^{-5}$ respectively. Significance at the levels $1 \%, 5 \%$ and $10 \%$ is shown by ${ }^{1},{ }^{2}$ and ${ }^{3}$, respectively. 
Table 2. Summary of seasonality and asymmetry

\begin{tabular}{lll}
\hline & Findings & Countries \\
\hline I & No asymmetry and no seasonality & $\operatorname{AUS}^{(a)}, \mathrm{FIN}^{(\mathrm{b})}(-), \mathrm{SPA}^{(\mathrm{a})}, \mathrm{SWE}_{\mathrm{UK}}$ \\
II & No asymmetry, seasonality only in mean & $\mathrm{JAP}^{(\mathrm{a})}(+), \mathrm{NET}^{(\mathrm{a})}, \mathrm{NZ}^{(\mathrm{a})}$ \\
III & No asymmetry, seasonality only in volatility & $\mathrm{BEL}^{(\mathrm{a})}, \mathrm{DEN}^{(\mathrm{a})}$ \\
IV & No asymmetry, seasonality in both mean and volatility & $\mathrm{AST}^{(\mathrm{a})}(+)$ \\
V & Asymmetry and no seasonality & $\mathrm{CAN}^{*}(+)$ \\
VI & Asymmetry and seasonality only in mean & $\mathrm{GER}^{* *}, \mathrm{HON}^{* *}$ \\
VII & Asymmetry and seasonality only in volatility & $\mathrm{FRA}^{*}, \mathrm{ITA}^{* *}(\mathrm{xx}), \mathrm{NOR}^{*}, \mathrm{SWI}^{* * *}$ \\
VIII & Asymmetry and seasonality in both mean and volatility & $\mathrm{USA}^{* * *}$ \\
\hline
\end{tabular}

Notes: AUS (Australia), AST (Austria), BEL (Belgium), CAN (Canada), DEN (Denmark), FIN (Finland), FRA (France), GER (Germany), HON (Hong Kong), ITA (Italy), JAP (Japan), NET (the Netherlands), NZ (New Zealand), NOR (Norway), SPA (Spain), SWE (Sweden), SWI (Switzerland), the UK, and the USA.

(a) ${ }^{\text {(b) }}$ and ${ }^{(\mathrm{c})}$ mean that the ARCH term is significantly positive $\left(\alpha^{+}>0\right)$ at the $1 \%, 5 \%$ and $10 \%$ levels, respectively.

$* * *, * *$ and $*$ denote significance of the leverage effect $\left(a^{-}>0\right)$ at the levels $1 \%, 5 \%$ and $10 \%$, respectively.

(xx) means there is a leverage effect and the estimated effect of positive forecast errors is also significantly positive at the $5 \%$ level $\left(a^{-}>0\right.$ and $\left.\alpha^{+}>0\right)$.

$(+)$ means that the estimated conditional volatility has a positive and significant on returns $(\gamma>0)$.

$(+)$ means that the estimated conditional volatility has a negative but insignificant effect on returns $(\gamma<0)$.

Without $(+)$ or $(-)$ assume that the estimated conditional volatility has a positive but insignificant effect $(\gamma=0)$.

Table 3. Day of the week effects on index returns and their conditional volatility

\begin{tabular}{llll}
\hline Day & Direction of effect & Return & Volatility \\
\hline Tuesday & + & $\mathrm{JAP}^{* *}(+)$ & $\mathrm{AST}^{* *}(+), \mathrm{DEN}^{*}, \mathrm{USA}^{*}$ \\
& - & $\mathrm{AST}^{*}(+), \mathrm{GER}^{*}(\mathrm{x}), \mathrm{NET}^{* * *}$ & $\mathrm{BEL}^{* *}, \mathrm{FRA}^{*}(\mathrm{x}), \mathrm{ITA}^{* *}(\mathrm{xx}), \mathrm{SWI}^{* *}(\mathrm{x})$ \\
Wednesday & + & $\mathrm{HON}^{*}(\mathrm{x}), \mathrm{JAP}^{*}(+), \mathrm{NZ}^{* * *}$ & - \\
& - & - & $\mathrm{ITA}^{* *}(\mathrm{xx})$ \\
Thursday & + & $\mathrm{JAP}^{*}(+), \mathrm{NZ}^{* *}$ & $\mathrm{AST}^{* *}(+), \mathrm{DEN}^{* *}, \mathrm{USA}^{* * *}$ \\
Friday & - & $\mathrm{NET}^{* * *}, \mathrm{USA}^{*}(\mathrm{x})$ & $\mathrm{ITA}^{* *}(\mathrm{xx})$ \\
& + & $\mathrm{NZ}^{* *}$ & $\mathrm{AST}^{* * *}(+)$ \\
& - & $\mathrm{AST}^{* *}(+), \mathrm{GER}^{*}(\mathrm{x})$ & $\mathrm{ITA}^{*}(\mathrm{xx}), \mathrm{NOR}^{*}(\mathrm{x})$ \\
\hline
\end{tabular}

Notes: AUS (Australia), AST (Austria), BEL (Belgium), CAN (Canada), DEN (Denmark), FIN (Finland), FRA (France), GER (Germany), HON (Hong Kong), ITA (Italy), JAP (Japan), NET (the Netherlands), NZ (New Zealand), NOR (Norway), SPA (Spain), SWE (Sweden), SWI (Switzerland), the UK, and the USA.

$* * *, * *$ and $*$ denote significance of the daily effects (compared to Monday) at the levels $1 \%, 5 \%$ and $10 \%$, respectively.

$(+)$ means that the estimated conditional volatility has a positive and significant effect on returns $(\gamma>0)$. Otherwise its effect is positive but insignificant. (x) means there is a leverage effect $\left(a^{-}>0\right)$.

(xx) means there is a leverage effect and the estimated effect of positive forecast errors is also significantly positive at the $5 \%$ level $\left(x^{--}>0\right.$ and $\left.\alpha^{+}>0\right)$.

(Denmark and the USA), and in one country on Fridays (Austria). In other countries, there are indistinguishable differences among volatilities across days of the week. The volatility is the lowest on Tuesdays in three countries (France, Italy and Switzerland) and on Fridays in Norway.

\section{CONCLUSION AND FURTHER RESEARCH}

Four hypotheses are simultaneously tested using the AR(p)-GJR-GARCH(1,1)-M model with day of the week effect dummies in both conditional mean and conditional volatility functions of daily index returns. Evidence is provided for predictable time varying daily volatility in the stock markets of 19 countries among which eight countries also exhibit a significant leverage effect on conditional volatility (H1 and H2). For eleven countries, a symmetric conditional volatility model, say, the standard GARCH(1,1) model suffices to model daily returns. There is a significantly positive relationship between index returns and their estimated conditional volatility in terms of standard deviation only in three countries, and no significant relationship at all for the rest of the sample (H3). The nature of the day of the week effects on returns and their conditional volatility differs greatly among countries and across days (H4). Thirteen countries exhibit seasonality in either mean returns (seven countries) or volatility (eight countries) or both (two countries). Each day is at least once reported to exhibit significant positive and negative effects in both mean and volatility with the exception that there is no negative effect on mean returns and no positive effect in volatility on Wednesdays. 
A fruitful area of research is to evaluate the out-ofsample forecasting performance of the GARCH and the GJR-GARCH models with international data. Note that we report that index returns in ten (eight) countries can be modelled better by the former (the latter) and the previous research on relative performance of competing models has reached different conclusions (Brailsford and Faff, 1996; Balaban, 1999). Such an investigation should explicitly include daily dummies in the conditional volatility functions and test their economic significance; i.e. whether the statistically significant in-sample findings regarding seasonality in volatility lead to better out-of-sample or future forecasts of volatility.

\section{ACKNOWLEDGMENTS}

Part of this research has been completed while Balaban was visiting the Deutsche Bundesbank. He thanks the staff of the Economics Department for their hospitality and gratefully acknowledges financial assistance by Konrad Adenauer Foundation and the Central Bank of the Republic of Turkey where he was working with the Research Department at the time of submission of this work.

\section{REFERENCES}

Aggarwal, R. and Rivoli, P. (1989) Seasonal and the day of the week effect in four emerging markets, Financial Review, 24, 541-50.

Agrawal, A. and Tandon, K. (1994) Anomalies or illusions? Evidence from stock markets in eighteen countries, Journal of International Money and Finance, 13, 83-106.

Baillie, R. T. and DeGennaro, R. P. (1990) Stock returns and volatility, Journal of Financial and Quantitative Analysis, 25, 203-14.

Balaban, E. (1999) Modeling and forecasting stock market volatility, Unpublished Manuscript, Johann Wolfgang Goethe University, Frankfurt/Main, Germany.

Bayar, A. and Kan, Ö. B. (1999) Day of the week effects: Evidence from nineteen countries, Paper presented at the Global Finance Conference, Istanbul, Turkey, April 1999.

Black, F. (1976) Studies of stock price volatility changes, Proceedings of the 1976 Meetings of the American Statistics Association, Business and Economics Statistics Section, 177-81.

Bollerslev, T., Chou, R. C. and Kroner, K. (1992) ARCH modeling in finance: a review of the theory and empirical evidence, Journal of Econometrics, 52, 5-59.

Bollerslev, T., Engle, R. F. and Nelson, D. B. (1994) ARCH models, in R. F. Engle and D. McFadden (eds), Handbook of Econometrics, Volume IV, North-Holland, Amsterdam, 2959-3038.

Bollerslev, T. and Wooldridge, J. (1992) Quasi-maximum likelihood estimation and inference in dynamic models with time varying covariances, Econometrics Reviews, 11, 143-72.

Brailsford, T. J. and Faff, R. W. (1996) An evaluation of volatility forecasting techniques, Journal of Banking and Finance, 20, 419-38.

Campbell, J. Y. and Hentschel, L. (1992) No news is good news: an asymmetric model of changing volatility in stock returns, Journal of Financial Economics, 31, 281-318.

Chan, K. C., Karolyi, G. A. and Stulz, R. (1992) Global financial markets and the risk premium on U.S. equity, Journal of Financial Economics, 32, 137-67.

Christie, A. A. (1982) The stochastic behavior of common stock variance: value, leverage and interest rate effects, Journal of Financial Economics, 10, 407-32.

Copeland, L. S. and Wang, P. (1994) Estimating daily seasonality in foreign exchange markets, Journal of Forecasting, 13, 51928.

Corhay, A. and Rad, A. T. (1994) Expected returns and volatility in European stock markets, International Review of Economics and Finance, 3, 45-56.

Dubois, M. and Louvet, P. (1996) The day of the week effect: international evidence, Journal of Banking and Finance, 20, 1463-84.

Duffee, G. R. (1995) Stock returns and volatility: a firm-level analysis, Journal of Financial Economics, 37, 399-420.

Engle, R. F. and Ng, V. K. (1993) Measuring and testing the impact of news on volatility, Journal of Finance, 48, 1749-78.

French, K. R., Schwert, G. W. and Stambaugh, R. (1987) Expected stock returns and volatility, Journal of Financial Economics, 19, 3-29.

Glosten, L. R., Jagannathan, R., and Runkle, D. E. (1993) On the relation between the expected value and the volatility of the nominal excess return on stocks, Journal of Finance, 48, 1779-801.

Hsieh, D. A. (1988) The statistical properties of daily exchange rates: 1974-1983, Journal of International Economics, 24, 129-45.

Jaffe, J. and Westerfield, R. (1985) The week-end effect in common stock returns: the international evidence, Journal of Finance, 40, 433-54.

Nelson, D. B. (1991) Conditional heteroscedasticity in asset returns: a new approach, Econometrica, 59, 347-70.

Peiro, A. (1994) Daily seasonality in stock returns: further international evidence, Economics Letters, 45, 227-32.

Theodossiou, P. and Lee, U. (1995) Relationship between volatility and expected returns across international stock markets, Journal of Business Finance and Accounting, 22, 289-300.

Wong, K. A., Hui, T. K. and Chan, C. Y. (1992) Day-of-the-week effects: evidence from developing stock markets, Applied Financial Economics, 2, 49-56.

Zakoian, J. M. (1994) Threshold heteroscedastic models, Journal of Economic Dynamics and Control, 18, 931-55. 